\title{
The Influence of Social Media Towards Emotions, Brand Relationship Quality, and Word of Mouth (WOM) on Concert's Attendees in Indonesia
}

\author{
Yulia Rahmadini ${ }^{1}$ and Rizal Edy Halim ${ }^{1 *}$ \\ ${ }^{1}$ Faculty of Economics and Business, Universitas Indonesia, Indonesia
}

\begin{abstract}
Social media has been developing significantly from year to year. In Indonesia, $72 \%$ of the internet users use the internet to access social media. This indicates that social media are effective brand communication and promotion tools. Music industry is one of the business industries which utilizes social media as communication and promotion tools, especially related to music concerts. The purpose of this study is to identify the impact and relationship of social media towards emotional attachment and brand relationship quality, in which both will be then compare towards word of mouth (WOM) on concert's attendees. This research uses descriptive design research conducted in one period (cross sectional design). Respondents of this study are 160 persons who attended concerts last year. The fivehypotheses research model in this study is tested using the Structural Equation Modelling (SEM). This research shows that social media interaction may result in emotional attachment. Emotional attachment felt by concert attendees may influence positively and significantly to brand relationship quality and creates word of mouth among the concert attendees.
\end{abstract}

\section{Introduction}

Across the time, social media keeps growing, pioneered by Friendster which dominated the usage of social media at that time. In 2004, Facebook was established, followed by Twitter in 2006. Facebook and Twitter are the most used and visited social media in the world. Right now, Facebook has 1.44 trillion active users, with 13\% increment from last year's record. As for Twitter, it has 308 million active users, with $18 \%$ increment form last year's record, reaching 500 million tweets per day.
Based on the data from The Indonesian Association of Internet Service Provider (Asosiasi Penyelenggara Jasa Internet Indonesia/APJII), up until the end of 2014, there are 88 million Internet users in Indonesia. The majority of these $72 \%$ internet users use internet to access the communication channel. Here, the social media is the main internet activity, where its usage exceeds other activities' like information browsing, chatting, news browsing and accessing the email.

A survey from Global Web Index presented that Indonesia is one of the most

\footnotetext{
* Corresponding author: rizaledy@gmail.com
} 
active countries in terms of social media usage. Indonesia has $79,7 \%$ active social media users, ahead of Filipina with for $78 \%$ active users, Malaysia with for $72 \%$ active users and China with $67 \%$ active users. Facebook still dominates social media market in Indonesia with $62 \%$ active users, followed by Twitter, Google Plus and LinkedIn [28]. The social media users in Indonesia are expected to reach 75,4 millions users in 2015 [29].

Social media is an internet-based application that established based on ideology framework and Web 2.0 technology which enables the idea creation and information exchange among its users [1]. According to [2] social media is an online community consists of internet users who have the same interest and have a desire to communicate with each other. Nowadays, some of social media that remain popular in Indonesia are Twitter, Facebook, Instagram, and Path. Additionally, Kaplan and Haenlein stated that social media has been the dominating topic in almost all aspects of business and industries.

Social media evolves to be the dominant means of digital communication [3]. However, as postulated by Pew Researcher Centre [4], among 67\% internet users who also use social media, only a few of them know about the role of social media in influencing emotions towards brand and whether social media based relationship could result in favourable result, for example positive word of mouth.

Based on previous illustration, music industry is one of industries that incorporate social media as a means of communication and promotion tools, especially in promoting music concert. The growth of music concert, especially in Jakarta, keeps escalating. Between 2012 and 2014, there are at least 20 music concerts held in each year. Almost all of the performers, who have held their concert, own social media account. One of the examples is Afgan, a young talented singer from Indonesia who just held his own concert titled "Dari Hati Afgan" in Februari 2015. He owns various type of social media like Twitter, Facebook and Instagram. In his Twitter, Afgan has 9.812 tweets that garnered 7.9 millions of followers. In his Facebook fan-page, Afgan garnered 1.5 million likes, while his Instagram account has 1.049 posts and garnered 476 thousands of followers. Besides Afgan, there is Katy Perry, an international musician, who also has held concert in Indonesia. Just like Afgan, Katy Perry owns various type of social media like Twitter, Facebook, Instagram, etc. In twitter, Katy Perry posts for 6.488 tweets and has garnered 69.7 million followers. Meanwhile, her Facebook fan-page is followed by 72 million of fans. As for her Instagram, it has 293 posts and garnered 19 million followers. There was at least 20 concerts held yearly between 2011 2015. Those music concerts utilize social media as a means of communication medium and promotion tools.

The previous illustration shows that social media is a right media to build emotions through interactions between the musicians and their fans. For the fans, social media is not only useful in exchanging information, but also in acquiring the most updated news about their favourite musician, such as their daily activities, rehearsal activities, concert schedule, etc. Knowing the fact that such activates could strengthen the relationship with their fans, often musicians will return to social media comment section to give love or likes, to retweet, and so forth.

Music concert as a brand has a distinctive characteristic, especially on its social media usage which occurs on certain time frame. As asserted by [5], the hedonic nature of music festivals turns them into an ideal context to empirically test the influence of emotions on brand relationship quality, as the value of the experience depends on the ability of the festival to engage one's subjectivity to arouse feelings or to provoke emotional reactions. Although there are only few studies on brand ownership and brand control related to music concerts, Mossberg and Getz asserted that brand can also be applied to concerts, as it can be applied to 
products, services, an organization, a person, a team or a symbol [6]. Here, it can be concluded that music concert can also be classified as a brand. According to [5], music concerts in particular are more popular than ever, where now they are attracting millions of fans.

Based on above explanation, this study wants to test and to analyse the effect of interaction between musicians and their fans in the social media on the level of emotional attachment, brand relationship quality, and word of mouth. First of all, this study will examine the effect of media social interaction on music concert. Emotion is the positive and negative feeling of a person [7] Next, this study will try to discover the effect of media social interaction and emotional attachment on music concert's attendees brand relationship quality, as per stated by [8], emotion is the component of brand relationship, whereas brand relationship quality a significant indicator for the strength and depth of consumers 'relational behaviour towards brands. The last but not least, this study will investigate the effect of emotional attachment and brand relationship quality on the music concert attendee's Word of Mouth. Here, word of mouth refers to a voluntary communication from the consumers where they promote a product or a brand to friends or relatives based on particular motives.

\section{Theoretical Background, Conceptual Model \& Hypotheses}

\subsection{Social Media Marketing}

Social media consist of channel and content that are spread through the interaction between individuals and organizations, in which social media creates a two-way interaction between the organization and its consumers [11]. The true power of social media is the notion of "we are all connected", which means that the communication occurs in social media is not a one-way communication, but rather a twoway communication whereas it enables a user to interact with not only other users, but also with the organization as well [10]. This is also supported by $\mathrm{Kim} \& \mathrm{Ko}$ [11] who stated that a brand and its consumers interact with each other without time, place and media boundary, that is the dynamic changes from a one-way communication to a twoway communication. The benefit of social media has been proven as the company using social media as a communication platform successfully improved its relationship with community and expanded consumer's prospect, actively and passively.

The transformation from product centric to customer centric emphasize the importance for the company to be more focus on its consumers, in which social media is considered as one of the best media to not only interact with the consumers, but also to build the image of the company. The importance of social media signify with the facilitation of immediate, interactive, and low-cost communications [12]. Thus, it require the company to increase the use of social media in its marketing activity. Moreover, it is also important to conduct the analysis of social media marketing activity and its influence towards the brand and the company as a whole. [11] explained that social media activity is influenced by 5 indicators, namely entertainment, interaction, usefulness, word of mouth and trendiness.

\subsection{Social Media Interaction}

Social media is the means of electronic communication which can be personalized by its user to share ideas, information, opinion and message [9]. Social media site like Facebook and microblogging site like Twitter have been the main source of communication to seek acquaintances and brands. These kind of social media site can be incorporated by the marketers and consumers to build a community which can attract other potential consumers to join. 
It is asserted that people visit social media for 3 major reasons [28]. The first reason is because of the brand or the product promotional campaign conducted by the company. The second reason is because the brand has a relevant content with the social media. The content is considered to be relevant when the delivered message has a meaning, or in the other words, the delivered message creates social connection. The third reason is because the popular and favourable content. The popularity of social media platform and content is important to make the users feel engaged with the brand. The fourth reason is because of the application used to access the social media. As the consumers can not automatically engage with the social media by themselves, the company has to analyse the characteristics of its target consumers then find the most effective social media platform to be utilized to interact with them.

In entertainment industry, Rothschild [19] observed that social media is utilized, organized and sensed by the company. It is discovered that more than a half $(57 \%)$ number of industries that utilize social media have higher income compared to those who did not. This finding supported previous study which asserted that when the brand initiates social media interaction with the consumers, it would lead to a positive impact for the brand. This positive impact can be in form of cognitive or affective [22]. Basically, cognitive is related to thinking, while affective is related to feeling. The affective system has 5 basic characteristics, which are: 1) Affective system has an immediate response towards the environment, 2) Society has a little control towards affective system of an individual, 3) Affective response can be observed physically from the individual's body motion, 4) Affective system can react to various kinds of stimulus, and 5) Although getting the same stimulus, the affective system of each individual is different, as it is based on each environment. One of the impact of affective system is emotion. Emotion is the feeling that triggers an individual to react towards internal or external stimulus.

\subsection{Emotion}

Emotion is a positive or negative feeling of an individual [7]. Emotion is part of consumer evaluation towards a stimulus which can be depicted as the consumer affective process [27]. The result of this evaluation will produce emotion towards the brand, and this emotion can be a positive one like happy, satisfied, and delighted or a negative one like angry, irritated, and upset. Human behaviour is easily affected by emotion. Consumers often feel so emotional and intuitive in their behaviour, in which it happens out of their consciousness. The marketers are interested to attract consumers emotionally as the emotionally-engaged consumers is desirable for the marketers.

Peter and Olson [22] asserted that in analysing the consumers, the marketers have to consider 3 aspects, namely consumer affective and cognitive state, consumer behaviour and consumer environment. Peter and Olson [22] also divided affective response into four types of response, which are emotion, special feeling, mood and evaluation. Emotion is the external factor that cannot be disregarded. Extra attention on the brand helps to create positive emotion, while negative emotions are the result of failing to meet a minimum standard [22].

Emotion towards the brand is one of the components of brand relationship. Consumers who have strong emotional relationship towards the brand are indirectly attached to that brand [20]. Emotional attachment with the brand makes individual to develop a delightful feeling towards the brand and to feel sad when the brand is not there [27]. The emotional relationship with the brand can be beyond the cognitive behaviour towards the brand [27], which is indicated by the strong relationships between brand and self-concept.

Emotional attachment can predict the strength of commitment towards the brand. 
However, this emotional attachment along with the consumer's personality can change the way consumers behave when they feel incompatible with the brand. Consumers who are emotionally-attached with the brand identify and recognize the brand really well so that they often show a quick dissatisfaction response when having a negative experience. This can endanger the emotional relationship between the consumers and the brand since the negative experience can lead to a strong negative reaction. This also shows that the bigger emotional attachment possessed by the consumers, the larger the tendency for them to lose trust and commitment toward the brand. Emotional attachment is the highest form of relationship as it is resulted from investment in the relationship between the company or brand and its consumers. To deal with this emotional attachment issue, the marketers can create a different product category with other brand, analyse the market better so that the consumers' needs are relevant with the brand, and create a more intimate relationship between the brand and the consumers.

\subsection{Brand Relationship Quality}

Brand relationship quality is also known as consumer-brand relationship or the relationship between the brand and its consumers. Brand relationship quality is depicted as the indicator for the strength and depth of consumers' relational behaviour towards brands [8]. Phau and Lau [23] illustrated that consumers project their personal characteristics into the brand when the brand itself can represent the consumers. Consumers who project themselves into the brand show a strong brand attachment. Similarly, [24] postulated that when consumers interact with brands, they develop an active relationship with those brands like people did with friends.

Brand relationship quality portrays the depth and strength of the relationship between the brand and its consumers. Brand relationship is considered superior in providing brand knowledge for the consumers and understanding consumers' needs [18]. Brand relationship as an interdependent, voluntary relationship between an individual and a brand, characterized by the unique history of the interaction and the anticipation of future event [18] . It means that the interdependent relationship between the consumers and the brand is a key indicator of the notion that relationship with the brand has the same quality with the relationship with other human.

This study asserted that the relationship quality between the brand and its consumers depicts the strong motivation towards the brand [18], in which this motivation influences the extensive evaluation and also identifies the condition and process of the mediation process for the brand relationship quality effect. The traditional brand researchers examined how the consumers see and evaluate the brand, checked the brand attitude, and evaluated the brand or the quality of the brand. These researcher noted that the consumers not only have the difference in brand perception, but also in the way of how they interact with the brand [18].

Conceptually, brand relationship quality has a richer and deeper meaning compared to the evaluation of a brand as a whole or behavioural intention. Brand relationship quality depicts the emotional attachment and strong motivation with the brand. There are a lot of concept to keep this relationship alive, which are more than just building positive feeling. The concepts are affective and sociomotive attachment, the consists of love/passion and self-connection; behavioural ties, the consists of interdependence and commitment; and supportive cognitive beliefs, the consists of intimacy and brand partner equity. Concepts of brand relationship quality, which are love/passion, self-connection, interdependence, commitment, intimacy, and brand partner quality [18]. 


\subsection{Word of Mouth}

Word of Mouth is the process of transferring information from one individual to other and has an important role in consumer decision making [19]. Brown and Reingen argued that WOM plays an important role in consumer behaviour and attitude formation [6]. WOM includes consumer attitude in sharing the brand, opinion or reaction towards business, product and service to others [20]. A positive WOM is a powerful marketing media for the company in influencing the consumers.

Some studies in recent decades found consistent results regarding the importance of personal interaction and WOM, especially in influencing market choice [20] and in distributing information about new product. WOM is usually created by the consumers who do not have personal agenda in recommending particular brand or product. Therefore, the recommendation via WOM is considered to be more credible and can gain more attention from the market [21].

When the consumers are satisfied and have positive attitude towards the brands, it does not automatically make them recommend the brand or involve in WOM.
The consumers have to feel motivated first in order to initiate the WOM. There are some factors that can make the consumers initiate the WOM, and even better, initiate the positive WOM. Understanding these factors can make the marketers to be more proactive in finding the best way to organize and influence the positive WOM, thus making the marketing communication work more effectively. The internal factors that can motivate consumers to initiate positive WOM are as following: strength of social ties, altruism, seeking confirmation of own judgement, and expressing sense of achievement [25].

Based on literature background above, we testing five hypothesis using the model in Figure 1 adopted from [26]:

H1: Social media interaction positively influence emotional attachment

$\mathrm{H} 2$ : Social media interaction positively influence brand relationship quality

H3: Emotional attachment positively influence brand relationship quality

H4: Emotional attachment positively influence word of mouth

H5: Brand relationship quality positively influence word of mouth

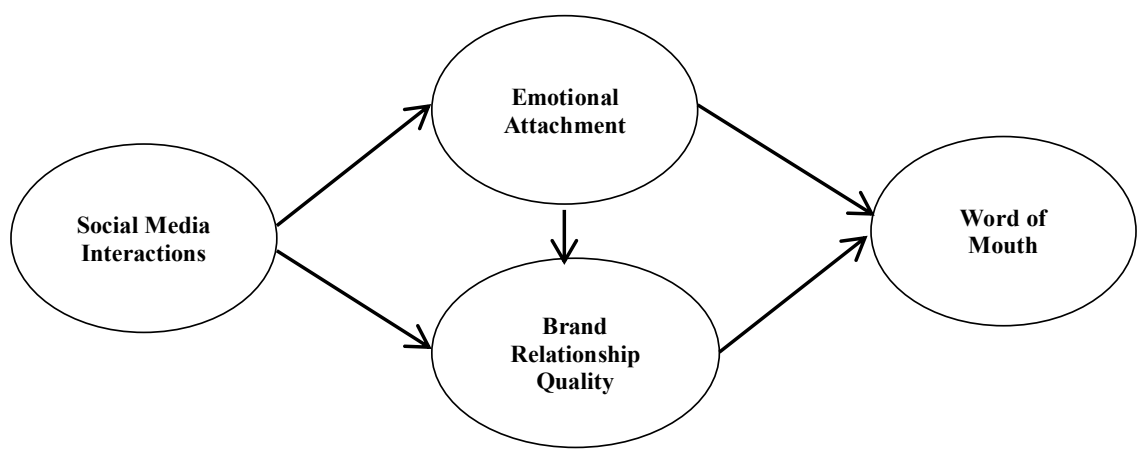

Fig. 1. Research Model 


\section{Method}

This study used descriptive research design with single cross sectional time frame. The data was collected by distributing the questionnaire directly and via online. The online questionnaires was distributed using Google docs. The respondents of this study were the one who have watched live concert at least once in this year, and followed the social media of their favorite musicians. The number of respondents needed in this study were 160 respondents. To acquire the respondents, this study utilized convenience sampling method, in which it gave freedom for the researcher to gather the sample from the places that are accessible and convenient for the researcher. For the places themselves, this study acquired the sample from Plenary Hall Jakarta and Artist Fanbase of Afgan and Taeyang. Here, the researcher came directly to the aforementioned place to meet the fans of Agfan and Taeyang.

The questionnaire of this study was measured by using a six-point Likert type scale. Emotion was measured by adapting items, which are affectionate, friendly, loved, peaceful, passionate, delightful, captivated, connected, bored and attached. As for brand relationship quality, it was measured by using 16 items from [18]. For word of mouth, it is a statement of respondents' willingness to recommend music concert from certain musicians to their friends or relatives.

\section{Results}

Out of 160 respondents, $84 \%$ are female and $16 \%$ are male. These 160 respondents are the one who at least have watched 1 concert in this year, and already followed the social media of their favourite musicians.

Next, this study conducted the goodness of fit analysis. The goodness of fit scores of this study are as follow: GFI $=0.71$ (marginal fit), RMSEA $=0.10$ (mediocre fit), NFI $=0.71$ (marginal fit). Also Parsmonious Fit Index shows a good fit score. The results show that the model has a good fit since it already fulfils 4 - 5 criteria of goodness of fit. A model has to meet at least 3 criteria of goodness of fit to be considered as a good fit model.

Figure 2 below depicts the $t$ value scores of each hypotheses used in the study. Four hypotheses in this study are supported as their t-values are $>1.96$, meanwhile 1 hypotheses is not supported as its t-value is $<1.96$.

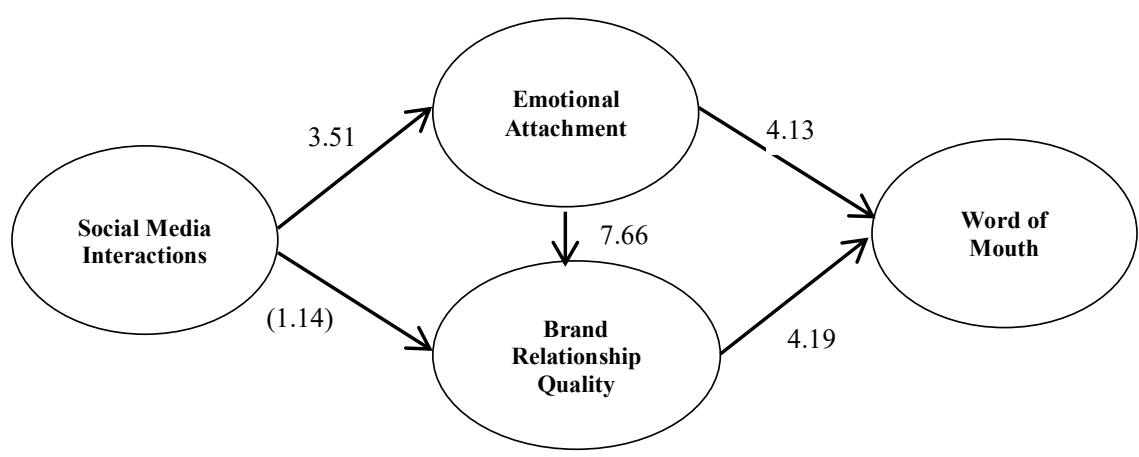

Fig. 2. T-Value Output 


\section{Conclusion}

Based on the results, several conclusions are presented to answer the objectives of the study. First of all, social media interaction has a positive and significant effect on emotional attachment. This significant effect is an indication that should the attendees of music concert experience a high level of interaction in the social media, their emotional attachment will be increased. Then, it is apparent that social media interaction has no significant and positive effect on brand relationship quality. This insignificant result might happen because the brand relationship quality, either related to the musicians or the concerts itself, has to be influenced first by the depth and strength of the relationship between the consumers and the brand [8].

As for emotional attachment, it has a positive and significant effect on brand relationship quality. This significant effect indicates that when the brand relationship of the consumers is high, then their emotional attachment will be high as well. Maintaining the relationship with the consumers will not only lead to positive feelings, but also to affective and sociemotive attachment which consist of love/passion and self-connection; behavioural ties, the consists of interdependence and commitment and supportive cognitive beliefs, the consists of intimacy and brand partner quality.

It is also proven that brand relationship quality has a positive and significant effect on word of mouth. This significant effect shows that when the brand relationship quality of the consumers is high, then their willingness to conduct word of mouth will be high as well. The same case also applied for emotional attachment, where it also has a positive and significant effect on word of mouth. This significant effect is an indication that should the emotional attachment of the consumers is high, then their willingness to conduct word of mouth will be high as well.

\subsection{Limitations and Recommendation for Future Research}

This study has several limitations that affect the result of the study as a whole. First, this study was only conducted in the Plenary Hall, Jakarta and within the fan base of Afgan and Taeyang. It would be better if it was conducted on several music concert venues instead of only one, and on more varied fan base, like female musicians fan base, for example Raisa, so that it would be more representative in explaining the music concert attendes' characteristics in general. Then, most of the questionnaires were only distributed on Jakarta area, thus most of the respondents were the residents of Jabodetabek and the total respondents acquired were only 160 . It would be better to gain a larger number of respondents in order to increase the reliability and validity of the study. Moreover, the distribution of physical questionnaires were only conducted on the fan base of Afgan and Taeyang, in which the majority of the members are female. This could create a bias on the study result as the majority of the respondents were female. For future studies, it is suggested that the distribution of the questionnaire is not only limited on the fan base of male musicians, but also on the fan base of female musicans in order to capture a larger and more balance picture of music attendes characteristics. It is also suggested to improve the range the area of study as to not limit it to Jabodetabek area only. By doing so, the result of study is believe to be richer. Doing the comparison across several areas will also improve the generalibility and external validity. Moreover, future studies can also add purchase intention as one of the variable in the research model. 


\section{References}

1. Aaker, David, Building Strong Brands (New York: The Free Press, 2006)

2. A. d'Astous, F.Colbert, E. d'Astous, International Journal of Arts Management 8 (2), 14-23 (2006)

3. A.M. Kaplan, M Haenlein, Users of The World, Unite! The Challenges and Opportunities of Social Media. Business Horizon, 53, 59-68 (2010)

4. A. Mecke, I. Lee, J.R. Baker jr., M.M. Banaszak Holl, B.G. Orr, Eur. Phys. J. E 14, 7 (2004)

5. B. Chappuis, B. Gaffey, P. Parvizi. Are your customers becoming digital junkies. McKinsey Quarterly, July, 1-4 (2011)

6. J. J. Brown, P. H. Reingen, Journal of Consumer Research 14, 350-362 (1987)

7. M. Cheung, M. M. Anitsal, I. Anitsal, Journal of Marketing Theory and Practice 15(3), 235-249 (2007)

8. Erdogmus, Irem Eren dan Cicek, Mesut, Procedia - Social and Behavioral Sciences 58, 1353 - 1360 (2012)

9. E. Smit, F. Bronner, M. Tolboom. Journal of Business Research 60, 627633 (2007)

10. S. Fournier, Journal of Consumer Research 24, (1998)

11. F. De Lillo, F. Cecconi, G. Lacorata, A. Vulpiani, EPL, 84 (2008)

12. F.P William. Social networking sites: How to Stay Safe Sites. Monthly Security tips Newsletter 4(3) (2009)

13. R. E. Halim, Elszuary Abrar Uzi Zulkarnain, Journal of Distribution Science 15(4), 15- 23 (2017)

14. R. E. Halim, The Impact of TrustDistrust toward Quality of Life: The Case of Poor and non-Poor Household in Indonesia. European Research Studies Journal Vol XX (Issue 3A) page 801-819. (2017)

15. J. A. Kim, E. Ko, Journal of Global Fashion Marketing 1, (2011)
16. L. Mossberg, D. Getz, Scandinavian Journal of Hospitality and Tourism 6 (4), 308-326 (2006)

17. T. D. L. Luigi, Propulsion physics (EDP Sciences, Les Ulis, (2009)

18. M. Ben Rabha, M.F. Boujmil, M. Saadoun, B. Bessaïs, Eur. Phys. J. Appl. Phys. 47(1), (2009)

19. K. D. Miller, F. Fabian, S. J. Lin, Strategic Management Journal 30, 305322 (2009)

20. J. P. Peter, J. C. Olson, Consumer Behavior 6th edition (McGraw-Hill. New York, 2002)

21. Pew Internet. Social media update (2014)

22. I. Phau, C. K. Lau, The Journal of Brand Management 8(6), 428-444 (2001)

23. R. Hanna, A. Rohm, V. L. Crittenden. We're all connected: The power of the social media ecosystem. Bussiness Horizon 2011, 7, 881 (2011)

24. M. L. Richins, T. Root-Shaffer, The Role of Involvement and Opinion Leadership in Consumer Word-ofMouth: An Implicit Model Made Explicit. Advance in Consumer Research, 15, 32-36. (1998)

25. Social media data, "user of social media" http://gsbipb.com, (accessed on 2014)

26. H. Simon, M. S. Roth, T. J. Madden, R. Hudson. The effects of social media on emotions, brand relationship quality, and word of mouth: An empirical study of music festival attendees. Tourism Management Vol. 47 (2015)

27. T. Suryanto, Investor Reaction and Fraud Prevention International Journal of Economic Perspectives 10(1), 138$150(2016)$

28. D. J. M. Thomson, C. Whan Park. Journal of Consumer Psychology 15(1), 77-91 (2005)

29. Y. Lee Y, J. Kim, JH. Back, Prev Med 48 (1), 86-90 (2009) 